\title{
Votation générale de FMH Services
}

\author{
FMH Services
}

Deutsch erschienen

in SÄZ Nr. 43/2005
Correspondance:

FMH Services

Burghöhe 1

CH-6208 Oberkirch
Les délibérations verbales de la votation générale de FMH Services ont porté sur les propositions suivantes:

- adoption du rapport de gestion 2004;

- adoption des comptes annuels 2004;

- décharge à l'administration.

Organe de publication: Bulletin des médecins suisses, $n^{\circ} 29 / 30$ du 27 juillet 2005

Délai du dépôt des votes: 30 août 2005 à la fiduciaire

Surveillance notariale: Markus Inauen, notaire, 6208 Oberkirch

Date du décompte des voix: mercredi 5 octobre 2005, dès 8 h.

Un vote séparé a eu lieu sur les quatre objets suivants. Les résultats sont les suivants:

\section{Proposition 1}

Souhaitez-vous donner votre accord à la proposition de l'administration de FMH Services d'accepter le rapport de gestion 2004?

La proposition est acceptée comme suit:

\begin{tabular}{lr} 
Bulletins délivrés & 2285 \\
\hline Bulletins blancs & 17 \\
\hline $\begin{array}{l}\text { Bulletins non valables } \\
\text { (pas d'expéditeur, pas de signature) }\end{array}$ & 1359 \\
\hline Bulletins valables & 909 \\
\hline Majorité absolue & 455 \\
\hline Oui & 882 \\
\hline Non & 27
\end{tabular}

La proposition est acceptée à une forte majorité.

\section{Proposition 2}

Souhaitez-vous donner votre accord à la proposition de FMH Services d'accepter les comptes annuels 2004 et le bénéfice net de Fr. $1418927 .-$ à attribuer aux réserves?
La proposition est acceptée comme suit:

\begin{tabular}{lr} 
Bulletins délivrés & 2285 \\
\hline Bulletins blancs & 18 \\
\hline $\begin{array}{l}\text { Bulletins non valables } \\
\text { (pas d'expéditeur, pas de signature) }\end{array}$ & 1359 \\
\hline Bulletins valables & 908 \\
\hline Majorité absolue & 455 \\
\hline Oui & 864 \\
\hline Non & 44
\end{tabular}

La proposition est acceptée à une forte majorité.

\section{Proposition 3}

Souhaitez-vous donner votre accord à la proposition de FMH Services d'accepter la recommandation de l'organe de révision d'accorder décharge à l'administration?

La proposition est acceptée comme suit:

\begin{tabular}{lr} 
Bulletins délivrés & 2285 \\
\hline Bulletins blancs & 18 \\
\hline $\begin{array}{l}\text { Bulletins non valables } \\
\text { (pas d'expéditeur, pas de signature) }\end{array}$ & 1359 \\
\hline Bulletins valables & 908 \\
\hline Majorité absolue & 455 \\
\hline Oui & 879 \\
\hline Non & 29
\end{tabular}

La proposition est acceptée à une forte majorité.

Le notaire assigné du canton de Lucerne confirme par la présente avoir été présent du début à la fin du décompte des voix, mercredi 5 octobre 2005, de 8 h 00 à 12 h 00 à la Chancellerie d'Oberkirch.

Les résultats de cette votation générale sont confirmés dans leur justesse et leur totalité. Ils seront publiés dans le Bulletin des médecins suisses. 6208 Oberkirch, le 5 octobre 2005

Le notaire: Markus Inauen 